\title{
Rs1008805 polymorphism of CYP19A1 gene is associated with the efficacy of hormone therapy in stage I-II and operable stage III breast cancer
}

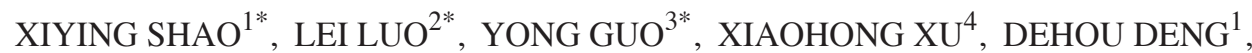 \\ JIANGUO FENG ${ }^{5}$, YUHENG DING ${ }^{3}$, HANZHOU MOU $^{5}$, PING HUANG ${ }^{1}$, LEI SHI ${ }^{1}$, YUAN HUANG ${ }^{1}$, \\ WEIWU YE ${ }^{1}$, CAIJIN LOU ${ }^{1}$, ZHANHONG CHEN ${ }^{1}$, YABING ZHENG ${ }^{1}$ and XIAOJIA WANG ${ }^{1}$ \\ ${ }^{1}$ Department of Medical Oncology, Zhejiang Cancer Hospital, Hangzhou, Zhejiang 310022; \\ ${ }^{2}$ Zhejiang Institute for Food and Drug Control, Hangzhou, Zhejiang 310052; ${ }^{3}$ Department of Medical Oncology, \\ The First Affiliated Hospital of Zhejiang Traditional Chinese Medical University, Hangzhou, Zhejiang 310006; \\ ${ }^{4}$ Clinical Laboratory; ${ }^{5}$ Cancer Research Institute, Zhejiang Cancer Hospital, Hangzhou, Zhejiang 310022, P.R. China
}

Received January 1, 2016; Accepted May 23, 2017

DOI: $10.3892 / 01.2017 .6984$

\begin{abstract}
It has been hypothesized that single nucleotide polymorphisms in CYP19A1 gene may alter aromatase activity and circulating steroid hormone levels in females. Therefore, it is biologically reasonable that CYP19A1 rs1008805 (A/G) polymorphism may be associated with the clinical outcome of hormone therapy. Genotyping for the CYP19A1 rs1008805 polymorphism was performed for 287 females with hormone receptor (HR)-positive early breast cancer, and potential associations were evaluated between CYP19A1 rs1008805 genotypes and disease-free survival (DFS). Based on the analysis of the whole cohort, no significant differences were observed between rs1008805 genotypes and DFS. However, in postmenopausal females, rs1008805 variants were significantly associated with DFS (AA vs. AG vs. GG, 89.2 vs. 58.2 vs. 32.7 months; $\mathrm{P}=0.019)$. In addition, when the population was divided into two cohorts, females with the GG variant exhibited a significantly poorer DFS [GG vs. AA or AG, 32.7 vs. 70.6 months; hazard ratio (HR), 3.613; 95\% confidence interval (CI), 1.380-9.457; P=0.005]. Furthermore, when adjusted for other patient features in multivariate analyses, GG genotype remained an independent prognostic marker for DFS (HR, 3.439; $95 \%$ CI, 1.251-9.456; $\mathrm{P}=0.017$ ). However, there were no significant differences in DFS between patients harboring the
\end{abstract}

Correspondence to: Professor Xiaojia Wang or Dr Yabing Zheng, Department of Medical Oncology, Zhejiang Cancer Hospital, 38 Guangji Road, Hangzhou, Zhejiang 310022, P.R. China

E-mail: wxiaojia0803@163.com

E-mail: zhengyabing@sina.com

*Contributed equally

Key words: breast cancer, aromatase, cytochrome P450 19A1, polymorphisms, predictive role minor allele and those with the homozygous common allele (AG or GG vs. AA, 52.4 vs. 89.2 months; HR, 1.288; 95\% CI, 0.705-2.353; $\mathrm{P}=0.408$ ). There were also no associations between rs1008805 polymorphism and DFS for premenopausal females. In conclusion, the homozygous minor allele (GG) of CYP19A1 rs1008805 was identified to be significantly associated with an inferior clinical outcome of hormone therapy in postmenopausal hormone receptor-positive patients with early breast cancer. If confirmed by further study, genotyping for CYP19A1 rs1008805 polymorphism may provide predictive information to improve the selection of endocrine treatment.

\section{Introduction}

Over the last three decades, the number of breast cancer cases has increased worldwide (1) to become the most likely cause of cancer mortality and morbidity in females (2). Increased levels of aromatase expression have been observed in breast lesions compared with normal breast tissue $(3,4)$ and alterations in aromatase expression are associated with the pathogenesis of breast cancer $(5,6)$.

Approximately two thirds of breast cancer cases overexpress estrogen receptors (ER) and/or progesterone receptors (PgR) (7,8). Consequently, endocrine therapy, including tamoxifen or aromatase inhibitors (AIs), has become an effective treatment for these patients. For decades, 5-year tamoxifen administration was the gold standard for the adjuvant endocrine treatment of breast cancer (9). More recently, postmenopausal patients have also had the option of receiving AIs as an alternative to tamoxifen, or following tamoxifen treatment (10). The presence and intensity of ER and/or PgR are useful predictive markers for the response to hormone therapy in clinical practice. Identification of more accurate biomarkers for the most efficient patient selection to exclude non-responsive patients remains crucial.

Aromatase, encoded by CYP19A1 gene, catalyzes the final step of the conversion from androgens into estrogens $(3,11,12)$. In premenopausal females, estrogen is predominantly produced 
by the ovary, with a small amount generated by the aromatization of adrenal and ovarian androgens in extragonadal tissue. Conversely, in postmenopausal females, the aromatization of androgens from extragonadal tissue becomes the prime origin of estrogen as the ovary ceases to function $(7,12,13)$.

It has previously been suggested that genetic polymorphisms in CYP19A1 gene were associated with aromatase activity as well as circulating steroid hormone levels in females $(3,11,12,14-16)$. Therefore, it is biologically reasonable that CYP19A1 gene polymorphism may be associated with the clinical outcome of hormone therapy. Population-based studies of CYP19A1 gene polymorphisms have revealed controversial results regarding their potential association with the therapeutic efficacy of endocrine treatment. Kuo et al (17) revealed that the A allele of CYP19A1 rs4646 was significantly in association with poorer distant disease-free survival rate $(\mathrm{P}<0.05)$ and marginally associated with shorter overall survival (OS; $\mathrm{P}=0.06)$ or disease-free survival (DFS; $\mathrm{P}=0.07$ ) in lymph node-negative, hormone receptor-positive patients with endocrine therapy. In addition, a study conducted by Garcia-Casado et al (18) estimated that the same variant was significantly associated with poorer progression-free survival (PFS) in patients with letrozole neoadjuvant therapy, and patients with genotypic variants of rs4646 were more frequently represented in the non-responder cohort (48 vs. 26\%). However, Liu et al (19) suggested that A allele of rs4646 was significantly associated with longer time to progression (TTP) and OS when assessed in patients with metastatic breast cancer (MBC) receiving anastrozole treatment, consistent with the study of Colomer et al (20), which indicated that TTP was significantly prolonged in patients with the minor $\mathrm{T}$ allele of CYP19A1 rs4646 compared with those with homozygous common allele (GG) from a cohort of postmenopausal MBC with letrozole administration.

CYP19A1 gene is located at chromosomal locus $15 \mathrm{q} 21.1$ and has a complex structure with a regulatory region that includes 10 tissue-specific non-coding upstream exons, with separate promoters, which regulate transcription in different tissues (21). Haplotype blocks 1 to 4 are located in this regulatory region. The rs1008805 polymorphism (A/G) is located in block 3 . The frequency of the minor allele $(\mathrm{G})$ is approximately $29.5 \%$ in Chinese females (22). A study conducted in Chinese population demonstrated that single nucleotide polymorphisms (SNPs) in block 1 and 2 of CYP19A1 gene were associated with the plasma levels of estrogen in postmenopausal females (23). Furthermore, it has been identified that the G allele of the rs1008805 SNP was significantly associated with the risk of breast cancer (24). Consequently, hypotheses were formulated that rs1008805 polymorphism may be associated with response of hormone therapy, which is still lacking supporting data.

Accordingly, a genetic analysis of CYP19A1 rs1008805 polymorphism was performed with a cohort of patients with hormone receptor-positive early breast cancer in order to elucidate whether rs1008805 variants were associated with the clinical outcome of hormone therapy.

\section{Patients and methods}

Study cohort and data. A total of 287 Chinese females with hormone receptor-positive stage I-II and operable stage III breast cancer, according to the tumor-node-metastasis stage classification (25), were enrolled in the present study between 1 April 2004 and 31 July 2010 at Zhejiang Cancer Hospital (Hangzhou, Zhejiang). All of the patients received hormone therapy. In brief, 250 patients received tamoxifen therapy and 37 received third-generation aromatase inhibitors. A total of $274(95.5 \%)$ of the patients received adjuvant chemotherapy, whereas $130(45.3 \%)$ received radiotherapy. A total of 274 patients $(95.5 \%)$ received chemotherapy including cyclophosphamide, doxorubicin and fluoracil or cyclophosphamide, epirubicin and fluoracil or doxorubicin, cyclophosphamide (AC) or fluoracil, epirubicin and cyclophosphamide followed by docetaxel or weekly paclitaxel treatment or docetaxel, doxorubicin and cyclophosphamide, cyclophosphamide and epirubicin or AC followed by docetaxel or weekly paclitaxel, $8(2.5 \%)$ with no chemotherapy and $6(2.0 \%)$ remained unknown. Human epidermal growth factor receptor-2 positive females received Trastuzumab treatment. A 3-mlperipheral blood sample was obtained and processed for DNA extraction in the Department of Oncology. The pathologic review, blood samples and genetic studies were approved by the institutional review board of Zhejiang Cancer Hospital. All patients provided written informed consent according to the guidelines of the Ethics Committee of Zhejiang Cancer Hospital.

DNA extraction and genotyping. Genomic DNA was extracted from peripheral blood with the AxyPrep Blood Genomic DNA Miniprep kit (Axygen; Corning Life Sciences, Union City, CA, USA). Genotyping was conducted through the Sequenom MassARRAY matrix-assisted laser desorption/ionization-time of flight mass spectrometry platform (Sequenom, San Diego, CA, USA) as previously described (26). Primers (5'-TCCTTA CCGAATCACTACCC-3' and 5'-CCTGCTATTACTTCC AACCC-3') and single base extensions were designed with Assay Designer software (version 3.0; Sequenom) and synthesized by Sangon Biotech Co., Ltd. (Shanghai, China).

Multiplex PCR was performed in $5 \mu \mathrm{l}$ volumes containing $10 \mathrm{ng}$ whole-genome-amplified genomic DNA, 2.5 pmol of each PCR primer, 0.1 unit of HotStar Taq polymerase (Qiagen GmbH, Hilden, Germany) and $2.5 \mu$ mol deoxynucleotides (dNTP; Qiagen $\mathrm{GmbH}$ ). Thermo cycling was performed at $94^{\circ} \mathrm{C}$ for $15 \mathrm{~min}$ followed by 45 cycles at $94^{\circ} \mathrm{C}$ for $20 \mathrm{sec}, 56^{\circ} \mathrm{C}$ for $30 \mathrm{sec}$ and $72^{\circ} \mathrm{C}$ for $1 \mathrm{~min}$ and a final incubation at $72^{\circ} \mathrm{C}$ for 3 min. Unincorporated dNTPs were deactivated with 0.3 units of shrimp alkaline phosphatase (Sequenom) followed by primer extension using $5.4 \mathrm{pmol}$ of each primer extension probe, $50 \mu \mathrm{mol}$ of the appropriate ddNTP combination, and 0.5 units of iPLEX enzyme (Sequenom). The extension reactions were performed at $94^{\circ} \mathrm{C}$ for $30 \mathrm{sec}$ and then $94^{\circ} \mathrm{C}$ for $5 \mathrm{sec}$, followed by 5 cycles at $52^{\circ} \mathrm{C}$ for $5 \mathrm{sec}$ and $80^{\circ} \mathrm{C}$ for $5 \mathrm{sec}$ for a total of 40 cycles, and then $72^{\circ} \mathrm{C}$ for $3 \mathrm{~min}$. A cation exchange resin was used to remove residual salt from the reactions. Purified primer extension reaction products were spotted onto a 384-well spectro CHIP using the Mass ARRAY Nano dispenser and determined by the mass spectrometer. Genotype analysis was performed in real time using MassARRAY RT software (version 3.0.0.4) and analyzed using MassARRAY Typer software (version 3.4; Sequenom).

Statistical analysis. The deviation from Hardy-Weinberg equilibrium (HWE) was assessed with Pearson's $\chi^{2}$ test using the HWE calculator described in Rodriguez et al (27). 
Follow-up data as available on 31 December 2014, were analyzed. DFS was defined as the date of the original surgery for breast cancer to the date of recurrence or mortality from any causes (28). DFS plots were produced using the Kaplan-Meier estimator method. Differences in median DFS were compared using the log-rank test.

Cox's regression analyses were conducted to estimate the hazard ratio (HR) and corresponding 95\% confidence interval (CI) for each variable. The multivariate-adjusted HR for relapse associated with the individual genotypes was examined for the groups subsequent to adjusting for other variables (lymph node positivity, tumor size $>2 \mathrm{~cm}$, negative hormone receptor status, human epidermal growth factor receptor-2 positive status, chemotherapy, hormone therapy, radiotherapy and body mass index $\geq 24$ ). These analyses were performed using the SPSS statistical software package (version 17.0; SPSS Inc., Chicago, IL, USA). $\mathrm{P}<0.05$ was considered to indicate a statistically significant difference.

\section{Results}

Patient features. A total of 287 females with hormone receptor-positive early breast cancer were enrolled in the present study, and the median age was 46 years (range, 20-73 years). As presented in Table I, 217 patients were premenopausal and 70 were postmenopausal. The clinicopathological features details are also listed in Table I.

In total, there were 145 patients with AA genotype, 124 with AG variant, and 18 with GG genotype. Genotype frequencies observed in our patient cohort were consistent with Hardy-Weinberg equilibrium ( $\mathrm{P}>0.05$, data not shown).

CYP19A1 rs1008805 polymorphism and DFS in the whole cohort. Based on the analysis of all patients, no significant differences were observed between rs1008805 genotypes and DFS (AA vs. AG vs. GG, 58.3 vs. 57.7 vs. 42.7 months; $\mathrm{P}=0.638$; Table II). In addition, there was no difference for DFS between patients with the minor allele, i.e., AG or GG, and those carrying the homozygous common allele AA (AG or GG vs. AA, 56.4 vs. 58.3 months; HR, 0.891; 95\% CI, 0.675-1.177; $\mathrm{P}=0.417$; Table II). Furthermore, when the population was split into two groups, one with GG variant and the other with AG or AA genotypes, there was no association between genotypes and DFS (GG vs. AG or AA, 42.7 vs. 58.0 months; HR, 1.092; 95\% CI, 0.593-2.010; $\mathrm{P}=0.777$; Table II).

CYP19A1 rs1008805 polymorphism and DFS in premenopausal patients. In premenopausal females, there was no significant association between rs1008805 genotypes and DFS (AA vs. AG vs. GG, 56.2 vs. 57.7 vs. 98.2 months; $\mathrm{P}=0.252$; Table II). When the patients were clustered into two groups, one with AA variant, and the other with AG or GG genotypes, no significant differences in DFS were evident between these subgroups (AG or GG vs. AA, 58.6 vs. 56.2 months; HR, 0.786; 95\%CI, 0.574-1.076; $\mathrm{P}=0.132$; Table II). Besides these, there were also no differences for DFS between patients with the homozygous minor allele (GG) and those carrying the common allele (GG vs. AA or AG, 98.2 vs. 56.4 months; HR, 0.648; 95\%CI, 0.286-1.468; $\mathrm{P}=0.294$; Table II).
CYP19A1 rs1008805 polymorphism and DFS in postmenopausal patients. In postmenopausal patients, rs1008805 genotypes were significantly associated with DFS (AA vs. AG vs. GG, 89.2 vs. 58.2 vs. 32.7 months; $\mathrm{P}=0.019$; Table II; Fig. 1). When the population was subdivided to two cohorts, the patients carrying GG variant had a significantly poorer DFS than those harboring AA or AG genotypes (GG vs. AA or AG, 32.7 vs. 70.6 months; HR, 3.613; 95\% CI, 1.380-9.457; $\mathrm{P}=0.005$; Table II; Fig. 2). Furthermore, being adjusted by patient features in multivariate analyses, GG genotype remained an independent prognostic marker for DFS (HR, 3.439; 95\% CI, 1.251-9.456; $\mathrm{P}=0.017$; Table II). However, there was no significant difference in DFS between females harboring the minor allele and those with the homozygous common allele in a univariate analysis (AG or GG vs. AA, 52.4 vs. 89.2 months; HR, 1.288; 95\% CI, 0.705-2.353; P=0.408; Table II).

\section{Discussion}

The results of the present study describe an association between rs1008805 variants of CYP19A1 gene and the efficacy of hormone therapy in postmenopausal females with early breast cancer. Previous studies attempting to identify the association between the expression of aromatase mRNA or protein and aromatase enzyme activity levels with therapeutic response have been indefinite and contradictory (17-20). In the present study, postmenopausal females with the homozygous GG variant of CYP19A1 rs1008805 exhibit a poorer DFS when compared with those carrying AG or AA genotypes. This difference was further confirmed by multivariate analysis. These findings are biologically reasonable when considering the essential role of CYP19A1 gene in estrogen metabolism, its potential activity in tumor growth and progression, as well as the potential functional significance of CYP19A1 genetic polymorphisms.

Several genotypic polymorphisms of CYP19A1 gene have generated inconsistent results with regard to their potential association with clinical outcome. Liu et al (19) demonstrated that TTP and OS were significantly improved in patients with the variant alleles of rs4646 (TT or TG) when compared with patients carrying the wild-type allele (GG) in 272 females with MBC treated with anastrozole. Besides, the data from Colomer et al (20) revealed that patients with the rare $\mathrm{T}$ allele of $\mathrm{rs} 4646$ had a TTP that was three times that of those harboring the homozygous common genotype (GG). However, the data from 95 consecutive postmenopausal females with stage II-III hormone receptor-positive breast cancer revealed that the $\mathrm{T}$ allele of rs4646 was associated with poorer response to letrozole neoadjuvant therapy, and the rare allele also appeared to be associated with shorter PFS when compared with those carrying the homozygous common allele, and this effect was particularly significant among elderly patients with no operation following letrozole induction (18). In contrast, Ghimenti et al (29) identified that rs6493497 and rs7176005 polymorphisms were not associated with the efficacy of anastrozole neoadjuvant therapy, aromatase mRNA basal expression level or expression alteration caused by therapy.

Estrogen serves a key role in the growth and progression of breast cancer through disrupting the processes of 
Table I. Association of CYP19A1 polymorphisms with clinical characteristics.

\begin{tabular}{|c|c|c|c|c|c|}
\hline \multirow[b]{2}{*}{ Characteristic } & \multirow[b]{2}{*}{$\mathrm{n}$} & \multicolumn{3}{|c|}{ Polymorphism type, n (\%) } & \multirow[b]{2}{*}{ P-value } \\
\hline & & AA & AG & GG & \\
\hline Total & 287 & $145(50.5)$ & $124(43.2)$ & $18(6.3)$ & \\
\hline Menopausal status & & & & & 0.902 \\
\hline Premenopausal & 217 & $111(76.6)$ & $93(75.0)$ & $13(72.2)$ & \\
\hline Postmenopausal & 70 & $34(23.4)$ & $31(25.0)$ & $5(27.8)$ & \\
\hline Tumor size, $\mathrm{cm}$ & & & & & 0.672 \\
\hline$\leq 2$ & 102 & $52(35.9)$ & $44(35.5)$ & $6(33.3)$ & \\
\hline$>2$ & 168 & $82(56.6)$ & $74(59.7)$ & $12(66.7)$ & \\
\hline Unknown & 17 & $11(7.6)$ & $6(4.8)$ & 0 & \\
\hline Lymph node invasion status & & & & & 0.853 \\
\hline Negative & 82 & $41(28.3)$ & $37(29.8)$ & $4(22.2)$ & \\
\hline Positive & 199 & $100(69.0)$ & $85(68.5)$ & $14(77.8)$ & \\
\hline Unknown & 6 & $4(2.8)$ & $2(1.6)$ & 0 & \\
\hline TNM stage & & & & & 0.266 \\
\hline I-II & 156 & $83(57.2)$ & $65(52.4)$ & $8(44.4)$ & \\
\hline III & 108 & $48(33.1)$ & $50(40.3)$ & $10(55.6)$ & \\
\hline Unknown & 23 & $14(9.7)$ & $9(7.3)$ & 0 & \\
\hline Estrogen receptor status & & & & & 0.266 \\
\hline Negative & 36 & $16(11.0)$ & $20(16.1)$ & 0 & \\
\hline Positive & 245 & $125(86.2)$ & $102(82.3)$ & $18(100.0)$ & \\
\hline Unknown & 6 & $4(2.8)$ & $2(1.6)$ & 0 & \\
\hline Progesterone receptor status & & & & & 0.861 \\
\hline Negative & 65 & $33(22.8)$ & $29(23.4)$ & $3(16.7)$ & \\
\hline Positive & 216 & $108(74.5)$ & $93(75.0)$ & $15(83.3)$ & \\
\hline Unknown & 6 & $4(2.8)$ & $2(1.6)$ & 0 & \\
\hline $\begin{array}{l}\text { Erb-B2 receptor tyrosine } \\
\text { kinase-2 status }\end{array}$ & & & & & 0.095 \\
\hline Negative & 174 & $79(54.5)$ & $83(66.9)$ & $12(66.7)$ & \\
\hline Positive & 70 & $37(25.5)$ & $30(24.2)$ & $3(16.7)$ & \\
\hline Unknown & 43 & $29(20.0)$ & $11(8.9)$ & $3(16.7)$ & \\
\hline Body mass index, $\mathrm{kg} / \mathrm{m}^{2}$ & & & & & 0.671 \\
\hline$<24$ & 159 & $84(57.9)$ & $64(52.0)$ & $11(61.1)$ & \\
\hline$\geq 24$ & 126 & $61(42.1)$ & $58(47.2)$ & $7(38.9)$ & \\
\hline Unknown & 2 & 0 & $2(0.8)$ & 0 & \\
\hline
\end{tabular}

cell differentiation and proliferation (30). Lønning et al (31) demonstrated that circulating estrogen levels were significantly associated with poorer DFS in postmenopausal patients. In a case-control cohort study, Rock et al (32) indicated that total estradiol, bioavailable estradiol and free estradiol circulating concentrations were associated with the risk of recurrence. Aromatase catalyzes the biosynthesis of estrogen in the adipose tissues through the conversion of androgens $(3,11,12)$. In addition, elevated levels of aromatase expression have been detected in malignant breast lesions compared with in normal breast tissue $(4,33)$. Besides, a number of previous studies have demonstrated that CYP19A1 gene polymorphisms may be associated with increased aromatase activity. Wang et al (34) and Gennari et al (35) indicated that rs6493497 and rs7176005 were associated with marked decrease in aromatase activity, and Kristensen et al (13) observed that longer TTTA repeats were associated with increased aromatase activity. A population-based and in vitro study revealed that a Thr364 mutation caused a sharp decrease in aromatase protein levels and activity, whereas a Cys264 mutation was associated with a slight decrease in allozyme activity. Furthermore, the mechanism by which non-synonymous SNPs interfere with the aromatase enzymatic activity was a consequence of an alteration in the aromatase protein level (36). Of note, it has been suggested that CYP19A1 polymorphisms were significantly associated with hormone levels $(14,15,37)$. Previous studies have indicated that the rs4646 may be associated with circulating hormone levels in postmenopausal breast cancer $(18,20)$. An analysis of five 
Table II. Association of CYP19A1 rs1008805 polymorphism with disease-free survival.

\begin{tabular}{|c|c|c|c|c|c|}
\hline \multirow[b]{2}{*}{ CYP19A1 polymorphism } & \multirow[b]{2}{*}{ Median DFS, months } & \multicolumn{2}{|c|}{ Univariate } & \multicolumn{2}{|c|}{ Multivariate $^{\mathrm{a}}$} \\
\hline & & $\mathrm{HR}(95 \% \mathrm{CI})$ & P-value & $\operatorname{HR}(95 \% \mathrm{CI})$ & P-value \\
\hline \multicolumn{6}{|l|}{ All patients } \\
\hline GG vs. AG vs. AA & $\begin{array}{c}42.7 \text { vs. } 57.7 \\
\text { vs. } 58.3\end{array}$ & $\begin{array}{l}\text { AG:AA,0.875 } \\
(0.657-1.167) \\
\text { GG:AA,1.030 } \\
(0.553-1.919)\end{array}$ & 0.638 & $\begin{array}{c}\text { AG:AA, } 0.794 \\
(0.586-1.075) \\
\text { GG:AA, 1.014 } \\
(0.540-1.902)\end{array}$ & 0.309 \\
\hline GG vs. AA/AG & 42.7 vs. 58.0 & $1.092(0.593-2.010)$ & 0.777 & $1.121(0.605-2.077)$ & 0.716 \\
\hline AG/GG vs. AA & 56.4 vs. 58.3 & $0.891(0.675-1.177)$ & 0.417 & $0.817(0.610-1.094)$ & 0.175 \\
\hline \multicolumn{6}{|l|}{ Premenopausal patients } \\
\hline GG vs. AG vs. AA & $\begin{array}{c}98.2 \text { vs. } 57.7 \\
\text { vs. } 56.2\end{array}$ & $\begin{array}{c}\text { AG:AA, } 0.811 \\
(0.587-1.120) \\
\text { GG:AA, } 0.590 \\
(0.258-1.353)\end{array}$ & 0.252 & $\begin{array}{c}\text { AG:AA, } 0.093 \\
(0.7430-0.526) \\
\text { GG:AA, 0.646 } \\
(0.279-1.495)\end{array}$ & 0.183 \\
\hline GG vs. AA/AG & 98.2 vs. 56.4 & $0.648(0.286-1.468)$ & 0.294 & $0.737(0.323-1.684)$ & 0.469 \\
\hline AG/GG vs. AA & 58.6 vs. 56.2 & $0.786(0.574-1.076)$ & 0.132 & $0.783(0.557-1.102)$ & 0.161 \\
\hline \multicolumn{6}{|l|}{ Postmenopausal patients } \\
\hline GG vs. AG vs. AA & $\begin{array}{l}58.2 \text { vs. } 89.2 \\
32.7 \text { vs. } 89.2\end{array}$ & $\begin{array}{c}\text { AG:AA, 3.750 } \\
(1.371-10.256) \\
\text { GG:AA, 1.086 } \\
(0.572-2.062)\end{array}$ & 0.019 & $\begin{array}{c}\text { AG:AA, 1.015 } \\
(0.476-2.165) \\
\text { GG:AA, 3.468 } \\
(1.160-10.369)\end{array}$ & 0.116 \\
\hline GG vs. AA/AG & 32.7 vs. 70.6 & $3.613(1.380-9.457)$ & 0.005 & $3.439(1.251-9.456)$ & 0.017 \\
\hline AG/GG vs. AA & 52.4 vs. 89.2 & $1.288(0.705-2.353)$ & 0.408 & $1.843(0.875-3.883)$ & 0.108 \\
\hline
\end{tabular}

${ }^{a}$ Adjusted for lymph node invasion positivity, tumor size $>2 \mathrm{~cm}$, negative hormone receptor status, Erb-B2 receptor tyrosine kinase-2-positive status, chemotherapy, hormone therapy, radiotherapy and body mass index $\geq 24$. DFS, disease-free survival; HR, hazard ratio; CI, confidence interval.

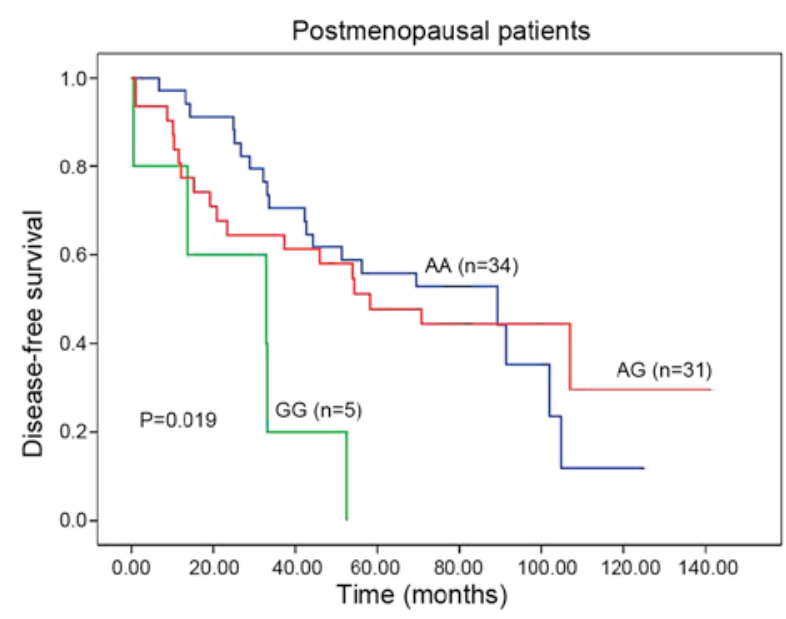

Figure 1. Kaplan-Meier estimator survival curves for postmenopausal patients. Disease-free survival of the patients grouped according to cytochrome P450 19A1 rs1008805 genotypes (AA vs. AG vs. GG).

large prospective cohort studies demonstrated that the A allele of rs727479 and rs749292 were significantly associated with elevated levels of estradiol and estrone (11). Haiman et al (38) revealed that females carrying 8-repeat allele of the TTTA polymorphism exhibited increased estrogen levels compared

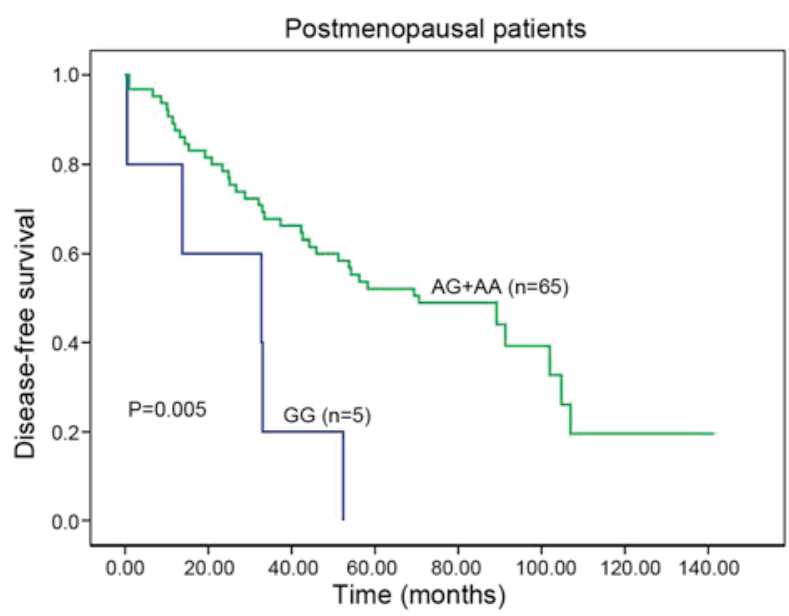

Figure 2. Kaplan-Meier estimator survival curves for postmenopausal patients. Disease-free survival of the postmenopausal females stratified by cytochrome P450 19A1 rs1008805 genotypes (AA and AG vs. GG).

with those harboring the 7-repeat allele. Cai et al (23) demonstrated that SNPs in block 1 and 2 of CYP19A1 gene were associated with plasma estrogen levels in postmenopausal Chinese females. Analysis of a comprehensive evaluation of majority variants in whole CYP19A1 gene revealed that a two 
SNP haplotype (rs749292-rs727479 A-A) was associated with a $15 \%$ high erestrogen levels in postmenopausal females (39).

The presence of the $\mathrm{G}$ allele at rs1008805 has been identified to be significantly associated with an increase in the risk of breast cancer (40). Additionally, Haiman et al (24) identified that the same genotype was marginally significant associated with breast cancer risk. The present study demonstrated that postmenopausal females with GG variant of CYP19AI rs1008805 have a poorer DFS for hormone therapy compared with those carrying AG or AA genotypes. The majority of SNPs are silent, and thus may not cause alterations to the function or the expression of mRNA (41). However, CYP19A1 rs1008805 SNP investigated in the present study appears to have an active effect. This maybe linked with an advantage structural alteration to the aromatase protein structure that causes it to be more active (42). A number of other mechanisms are also possible, including an alteration to a DNA-binding site $(43,44)$, mRNA stabilization, splicing or folding alterations, and the modification of transcriptional and post-translational regulation (45-47).

On the basis of these previous studies and the results of the present study, it is hypothesized that CYP19A1 rs1008805 G SNP may result in elevated aromatase activity, higher protein levels, and thus an increase in circulating estrogen concentrations in postmenopausal females. It is a plausible hypothesis that the GG variant of rs1008805 may cause diminished functional efficacy of hormone therapy when used at the recommended dose, allowing estrogen synthesis to be maintained in the subgroup of postmenopausal patients carrying the GG genotype of rs1008805 during endocrine treatment. However, the presumed difference in estrogen level would be decreased between the premenopausal patients with the GG variant and those with AA or AG, as estrogen is predominantly generated by the ovary in premenopausal females, perhaps causing the effect of CYP19A1 variants on estrogen levels to be negligible for this group. Therefore, the GG genotype was associated with decreased DFS in postmenopausal patients with hormone therapy, whereas there was no significant association between rs1008805 genotypes and DFS for premenopausal females receiving endocrine treatment.

To conclude, it was demonstrated that the GG genotype of rs1008805 SNP in the first exon of CYP19A1 gene was significantly associated with inferior DFS in postmenopausal females with hormone therapy. Testing for CYP19A1 gene rs1008805 SNP as a predictive marker for the response to endocrine therapy in hormone receptor-positive early breast cancer warrants a larger independent prospective clinical evaluation.

\section{Acknowledgements}

The present study was supported by the Zhejiang Provincial Natural Science Foundation (grant nos. Y2101312, and LY17H160041), the Zhejiang Provincial Medical Science and Technology program (grant nos. 2010QNA006, 2015RCB005 and 2016KYA046), the Zhejiang Science and Technology program (grant no. 2016C33199), the Zhejiang Traditional Chinese Medicine Science and Technology program (grant nos. 2013ZB022 and 2014ZB019) and the
Special fund of Wu Jieping Medical Foundation Clinical Research (grant no. 320.670010007). This abstract was presented at the GAP2016 Challenging Cancer Meeting, 24-28 April 2016, Barretos and São Paulo, Brazil and was published as Abstract no. 666.

\section{References}

1. Pedraza AM, Pollan M, Pastor-Barriuso R and Cabanes A: Disparities in breast cancer mortality trends in a middle income country. Breast Cancer Res Treat 134: 1199-1207, 2012.

2. Hortobagyi GN, de la Garza Salazar J, Pritchard K, Amadori D, Haidinger R, Hudis CA, Khaled H, Liu MC, Martin M, Namer M, et al: The global breast cancer burden: Variations in epidemiology and survival. Clinical Breast Cancer 6: 391-401, 2005.

3. Bulun SE, Sebastian S, Takayama K, Suzuki T, Sasano H and Shozu M: The human CYP19 (aromatase P450) gene: Update on physiologic roles and genomic organization of promoters. J Steroid Biochem Mol Biol 86: 219-224, 2003.

4. Irahara N, Miyoshi Y, Taguchi T, Tamaki Y and Noguchi S: Quantitative analysis of aromatase mRNA expression derived from various promoters (I.4, I.3, PII and I.7) and its association with expression of TNF-alpha, IL-6 and COX-2 mRNAs in human breast cancer. Int J Cancer 118: 1915-1921, 2006.

5. O'Neill JS, Elton RA and Miller WR: Aromatase activity in adipose tissue from breast quadrants: A link with tumour site. $\mathrm{Br}$ Med J (Clin Res Ed) 296: 741-743, 1988.

6. Agarwal VR, Bulun SE, Leitch M, Rohrich R and Simpson ER: Use of alternative promoters to express the aromatase cytochrome P450 (CYP19) gene in breast adipose tissues of cancer-free and breast cancer patients. J Clin Endocrinol Metab 81: 3843-3849, 1996.

7. Bulun SE, Lin Z, Imir G, Amin S, Demura M, Yilmaz B, Martin R, Utsunomiya H, Thung S, Gurates B, et al: Regulation of aromatase expression in estrogen-responsive breast and uterine disease: From bench to treatment. Pharmacol Rev 57: 359-383, 2005.

8. Toniolo PG, Levitz M, Zeleniuch-Jacquotte A, Banerjee S, Koenig KL, Shore RE, Strax P and Pasternack BS: A prospective study of endogenous estrogens and breast cancer in postmenopausal women. J Natl Cancer Inst 87: 190-197, 1995.

9. Goldhirsch A, Gelber RD and Coates AS: What are the long-term effects of chemotherapy and hormonal therapy for early breast cancer? Nat Clin Pract Oncol 2: 440-441, 2005.

10. Burstein HJ, Prestrud AA, Seidenfeld J, Anderson H, Buchholz TA, Davidson NE, Gelmon KE, Giordano SH, Hudis CA, Malin J, et al: American society of clinical oncology clinical practice guideline: Update on adjuvant endocrine therapy for women with hormone receptor-positive breast cancer. J Clin Oncol 28: 3784-3796, 2010.

11. Zhao Y,Mendelson CR and Simpson ER: Characterization of the sequences of the human CYP19 (aromatase) gene that mediate regulation by glucocorticoids in adipose stromal cells and fetal hepatocytes. Mol Endocrinol 9: 340-349, 1995.

12. Santen RJ, Brodie H, Simpson ER, Siiteri PK and Brodie A: History of aromatase: Saga of an important biological mediator and therapeutic target. Endocr Rev 30: 343-375, 2009.

13. Kristensen VN, Harada N, Yoshimura N, Haraldsen E, Lonning PE, Erikstein B, Karesen R, Kristensen $\mathrm{T}$ and Borresen-Dale AL: Genetic variants of CYP19 (aromatase) and breast cancer risk. Oncogene 19: 1329-1333, 2000.

14. Haiman CA, Dossus L, Setiawan VW, Stram DO, Dunning AM, Thomas G, Thun MJ, Albanes D, Altshuler D, Ardanaz E, et al: Genetic variation at the CYP19A1 locus predicts circulating estrogen levels but not breast cancer risk in postmenopausal women. Cancer Res 67: 1893-1897, 2007.

15. Dunning AM, Dowsett M, Healey CS, Tee L, Luben RN, Folkerd E, Novik KL, Kelemen L, Ogata S, Pharoah PD, et al: Polymorphisms associated with circulating sex hormone levels in postmenopausal women. J Natl Cancer Inst 96: 936-945, 2004.

16. Mitrunen K and Hirvonen A: Molecular epidemiology of sporadic breast cancer. The role of polymorphic genes involved in oestrogen biosynthesis and metabolism. Mutat Res 544: 9-41, 2003. 
17. Kuo SH, Yang SY, Lien HC, Lo C, Lin CH, Lu YS, Cheng AL, Chang KJ and Huang CS: CYP19 genetic polymorphism haplotype AASA is associated with a poor prognosis in premenopausal women with lymph node-negative, hormone receptor-positive breast cancer. Biomed Res Int 2013: 562197, 2013.

18. Garcia-Casado Z, Guerrero-Zotano A, Llombart-Cussac A, Calatrava A, Fernandez-Serra A, Ruiz-Simon A, Gavila J, Climent MA, Almenar S, Cervera-Deval J, et al: A polymorphism at the 3'-UTR region of the aromatase gene defines a subgroup of postmenopausal breast cancer patients with poor response to neoadjuvant letrozole. BMC Cancer 10: 36, 2010.

19. Liu L, Bai YX, Zhou JH, Sun XW, Sui H, Zhang WJ, Yuan HH, Xie R, Wei XL, Zhang TT, et al: A polymorphism at the 3'-UTR region of the aromatase gene is associated with the efficacy of the aromatase inhibitor, anastrozole, in metastatic breast carcinoma. Int J Mol Sci 14: 18973-18988, 2013

20. Colomer R, Monzo M, Tusquets I, Rifa J, Baena JM, Barnadas A, Calvo L, Carabantes F, Crespo C, Munoz M, et al: A single-nucleotide polymorphism in the aromatase gene is associated with the efficacy of the aromatase inhibitor letrozole in advanced breast carcinoma. Clin Cancer Res 14: 811-816, 2008.

21. Simpson ER: Aromatase: Biologic relevance of tissue-specific expression. Semin Reprod Med 22: 11-23, 2004.

22. Long JR, Kataoka N, Shu XO, Wen W, Gao YT, Cai Q and Zheng W: Genetic polymorphisms of the CYP19A1 gene and breast cancer survival. Cancer Epidemiol Biomarkers Prev 15: 2115-2122, 2006.

23. Cai H, Shu XO, Egan KM, Cai Q, Long JR, Gao YT and Zheng W: Association of genetic polymorphisms in CYP19A1 and blood levels of sex hormones among postmenopausal Chinese women. Pharmacogenet Genomics 18: 657-664, 2008.

24. Haiman CA, Stram DO, Pike MC, Kolonel LN, Burtt NP, Altshuler D, Hirschhorn J and Henderson BE: A comprehensive haplotype analysis of CYP19 and breast cancer risk: The multiethnic cohort. Hum Mol Genet 12: 2679-2692, 2003.

25. Theriault RL, Carlson RW, Allred C, Anderson BO, Burstein HJ, Edge SB, Farrar WB, Forero A, Giordano SH, Goldstein LJ, et al: Breast cancer, version 3.2013: Featured updates to the NCCN guidelines. J Natl Compr Canc Netw 11: 753-761, 2013.

26. Carbonnelle E, Mesquita C, Bille E, Day N, Dauphin B, Beretti JL, Ferroni A, Gutmann L and Nassif X: MALDI-TOF mass spectrometry tools for bacterial identification in clinical microbiology laboratory. Clin Biochem 44: 104-109, 2011.

27. Rodriguez S, Gaunt TR and Day IN: Hardy-Weinberg equilibrium testing of biological ascertainment for Mendelian randomization studies. Am J Epidemiol 169: 505-514, 2009.

28. Hudis CA, Barlow WE, Costantino JP, Gray RJ, Pritchard KI, Chapman JA, Sparano JA, Hunsberger S, Enos RA, Gelber RD, et al: Proposal for standardized definitions for efficacy end points in adjuvant breast cancer trials: The STEEP system. J Clin Oncol 25: 2127-2132, 2007.

29. Ghimenti C, Mello-Grand M, Grosso E, Scatolini M, Regolo L, Zambelli A and Chiorino G: Regulation of aromatase expression in breast cancer treated with anastrozole neoadjuvant therapy. Exp Ther Med 5: 902-906, 2013.

30. Bouchard MF, Taniguchi $\mathrm{H}$ and Viger RS: Protein kinase A-dependent synergism between GATA factors and the nuclear receptor, liver receptor homolog-1, regulates human aromatase (CYP19) PII promoter activity in breast cancer cells. Endocrinology 146: 4905-4916, 2005.

31. Lønning PE, Helle SI, Johannessen DC, Ekse D and Adlercreutz H: Influence of plasma estrogen levels on the length of the disease-free interval in postmenopausal women with breast cancer. Breast Cancer Res Treat 39: 335-341, 1996.

32. Rock CL, Flatt SW, Laughlin GA, Gold EB, Thomson CA, Natarajan L, Jones LA, Caan BJ, Stefanick ML, Hajek RA, et al: Reproductive steroid hormones and recurrence-free survival in women with a history of breast cancer. Cancer Epidemiol Biomarkers Prev 17: 614-620, 2008.
33. de Jong PC, Blankenstein MA, van de Ven J, Nortier JW, Blijham GH and Thijssen JH: Importance of local aromatase activity in hormone-dependent breast cancer: A review. Breast 10: 91-99, 2001

34. Wang L, Ellsworth KA, Moon I, Pelleymounter LL, Eckloff BW, Martin YN, Fridley BL, Jenkins GD, Batzler A, Suman VJ, et al: Functional genetic polymorphisms in the aromatase gene CYP19 vary the response of breast cancer patients to neoadjuvant therapy with aromatase inhibitors. Cancer Res 70: 319-328, 2010.

35. Gennari L, Masi L, Merlotti D, Picariello L, Falchetti A, Tanini A, Mavilia C, Del Monte F, Gonnelli S, Lucani B, et al: A polymorphic CYP19 TTTA repeat influences aromatase activity and estrogen levels in elderly men: Effects on bone metabolism. J Clin Endocrinol Metab 89: 2803-2810, 2004.

36. Ma CX, Adjei AA, Salavaggione OE, Coronel J, Pelleymounter L, Wang L, Eckloff BW, Schaid D, Wieben ED, Adjei AA, et al: Human aromatase: Gene resequencing and functional genomics. Cancer Res 65: 11071-11082, 2005.

37. Tworoger SS, Chubak J, Aiello EJ, Ulrich CM, Atkinson C, Potter JD, Yasui Y, Stapleton PL, Lampe JW, Farin FM, et al: Association of CYP17, CYP19, CYP1B1, and COMT polymorphisms with serum and urinary sex hormone concentrations in postmenopausal women. Cancer Epidemiol Biomarkers Prev 13: 94-101, 2004

38. Haiman CA, Hankinson SE, Spiegelman D, De Vivo I, Colditz GA, Willett WC, Speizer FE and Hunter DJ: A tetranucleotide repeat polymorphism in CYP19 and breast cancer risk. Int J Cancer 87: 204-210, 2000.

39. Haiman CA, Hsu C, de Bakker PI, Frasco M, Sheng X, Van Den Berg D, Casagrande JT, Kolonel LN, Le Marchand L, Hankinson SE, et al: Comprehensive association testing of common genetic variation in DNA repair pathway genes in relationship with breast cancer risk in multiple populations. Hum Mol Genet 17: 825-834, 2008.

40. Talbott KE, Gammon MD, Kibriya MG, Chen Y, Teitelbaum SL, Long CM, Gurvich I, Santella RM and Ahsan H: A CYP19 (aromatase) polymorphism is associated with increased premenopausal breast cancer risk. Breast Cancer Res Treat 111: 481-487, 2008.

41. Erichsen HC and Chanock SJ: SNPs in cancer research and treatment. Br J Cancer 90: 747-751, 2004

42. Tsigelny IF, Kotlovyi V and Wasserman L: SNP analysis combined with protein structure prediction defines structure-functional relationships in cancer related cytochrome P450 estrogen metabolism. Curr Med Chem 11: 525-538, 2004.

43. Bond GL, Hu W, Bond EE, Robins H, Lutzker SG, Arva NC, Bargonetti J, Bartel F, Taubert H, Wuerl P, et al: A single nucleotide polymorphism in the MDM2 promoter attenuates the p53 tumor suppressor pathway and accelerates tumor formation in humans. Cell 119: 591-602, 2004.

44. Skorupski P, Krol J, Starega J, Adamiak A, Jankiewicz K and Rechberger T: An alpha-1 chain of type I collagen Sp1-binding site polymorphism in women suffering from stress urinary incontinence. Am J Obstet Gynecol 194: 346-350, 2006.

45. Chen X, Truong TT, Weaver J, Bove BA, Cattie K, Armstrong BA, Daly $\mathrm{MB}$ and Godwin AK: Intronic alterations in BRCA1 and BRCA2: Effect on mRNA splicing fidelity and expression. Hum Mutat 27: 427-435, 2006.

46. Duan J, Wainwright MS, Comeron JM, Saitou N, Sanders AR, Gelernter J and Gejman PV: Synonymous mutations in the human dopamine receptor D2 (DRD2) affect mRNA stability and synthesis of the receptor. Hum Mol Genet 12: 205-216, 2003

47. Jin Y, Dietz HC, Montgomery RA, Bell WR, McIntosh I, Coller B and Bray PF: Glanzmann thrombasthenia. Cooperation between sequence variants in cis during splice site selection. J Clin Invest 98: 1745-1754, 1996. 